\title{
Theoretical Explanation For Success Of Deep-Level-Learning Study Tours
}

Harald Bergsteiner, Macquarie University, Australia

Gayle C. Avery, (Email: Gayle.Avery@mgsm.edu.au), Macquarie University, Australia

\begin{abstract}
Study tours can help internationalize curricula and prepare students for global workplaces. We examine benefits of tours providing deep-level learning experiences rather than industrial tourism using five main theoretical frameworks to highlight the diverse learning benefits associated with intensive study tours in particular. Relevant theoretical models are Kolb's Experiential Learning Model, Gregorc's Style Delineator, Felder-Silverman Index of Learning Styles, VARK Questionnaire, and Dunn and Dunn's Learning Style Model. Intensive study tours address nearly all the styles and techniques encompassed by these models.
\end{abstract}

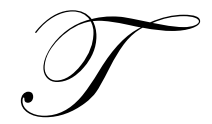

he call for high caliber global leaders is getting louder (Cornuel, 2007). Gregersen, Morrison and Black (1998: 6) concluded from their survey of global leadership: "The basic mental process for development [of global leaders] is to understand the world, not just one country...that requires both some rearranging and stretching of our mind-sets". Part of stretching mindsets includes understanding how business is done in different cultures, and appreciating cultural and business diversity (Cales, 2000; Goldsmith, Walt and Doucet, 1999/2000). Global leaders can be developed on the job through international assignments and training, but their development can also begin with travel in which they are exposed to local conditions abroad (Oddou, Mendenhall and Ritchie, 2000). Increasingly, tertiary teaching institutions are responding by including overseas study tours in their curriculum, in addition to study abroad programs of varying length.

This paper focuses on the relatively short-term study tour as an educational tool to help prepare managers for a global world. Study tours are not new in business education, but today providing intercultural learning experiences for managers is growing in importance (Thomas, 2007), making travel experiences likely to increase. Two kinds of tours and their pedagogic implications are discussed. We will see that choosing from a multiplicity of potential teaching/learning styles and approaches, such as doing 'industrial tourism' versus conducting intensive study tours, results in quite different learning outcomes for participants. This paper describes the rationale behind developing study tours as intensive learning experiences, compared with industrial tourism, and illustrates some of the benefits and problems in staging such events. Surface and deep levels of learning, and maximizing student learning, are discussed.

A useful theoretical setting is provided by Hawk and Shah's (2007) description, review, and comparison of six prominent learning style models found in higher education - Kolb's Experiential Learning Model, Gregorc's Style Delineator, the Felder-Silverman Index of Learning Styles, the VARK Questionnaire, Dunn and Dunn's Learning Style Model, plus Duff's revised Studying Inventory Model. These models are used in the next section to help explain and validate the learning experience provided by study tours, particularly tours that provide deep-level learning.

\section{RELATING LEARNING MODELS TO STUDY TOUR EXPERIENCES}

Kolb's Experiential Learning Theory posits that learning style refers to the "generalized differences in learning orientation based on the degree to which people emphasize the four modes of the learning process" (Kolb, 1984: 76). Hawk and Shah report that research shows that this model has both validity and reliability. Study tours touch all four modes of the model - company visits constitute concrete experience; debriefings and logs are a form 
of reflective observation; individual students' reports on applying lessons learned to their own organization represent abstract conceptualization; and the implementation of such proposals entails active experimentation, which in turn leads to concrete experience, thus setting up a learning cycle. Kolb and subsequent authors list a range of activities that fall within these four domains such as: lectures, problem sets, readings, films, simulations, laboratories, observations, and field work. Traditional classroom teaching, even if interactive, tends to be short on these, despite research showing that experiential learning can enhance learning (e.g. Kayes, Kayes and Kolb, 2005). The experiential component of study tours therefore addresses a teaching gap.

Gregorc's (1997) Learning Style Model depicts manipulable learning predispositions that can be plotted along four bi-polar and continuous dimensions, namely: abstract and concrete perception, sequential and random ordering, deductive and inductive processing, and separative and associative relationships. Hawk and Shaw (2007) report only moderate support for reliability, and partial and limited support for validity. Pairings of these bi-polar dimensions give rise to four learning styles: Concrete-Sequential (CS), Abstract-Sequential (AS), Abstract-Random (AR), and Concrete-Random (CR). CS learners prefer direct, hands-on experience, want order and logical sequences. AS learners appreciate ideas and symbols, think logically and sequentially, and avoid distractions. $A R$ learners focus attention on people and surroundings, prefer wide-ranging discussions and conversations, and want time for reflecting on experiences. CR learners are experimental and risk-takers, they like to explore unstructured problems, solve them through intuitive leaps, and use trial and error. Butler (1986) lists a range of activities that fall within these four domains. Again, the study tour format with its lectures, preparatory work, briefings, role-plays, discussion sessions, plant visits, and debriefings provides opportunities for all four learning preferences. Hawk and Shah's own research using Gregorc's Learning Style Model shows 52\% of their evening MBA students prefer the CS style, 20\% prefer CR, 15\% AS, and 12\% AR. Field trips and study tours are a key component of the CS, that is, the preferred, style, which could help account for the high approval rate of study tours.

Fleming's (2001) VARK Model is a sensory model that proposes that learning involves four ways in which people take in and give out information: visual, aural, read/write, and kinesthetic. Based on individual's preferences, these can be plotted to reveal learning profiles that can be highly skewed, balanced, or variable across the four dimensions. Fleming lists a range of activities that fall within these four domains. Fleming's own research supports the use of instruments associated with this model to identify learning preferences, and reports an improvement in student performance when learning activities are matched to students' preferred learning styles. Again, the study tour format provides opportunities for all four learning preferences with the aural, read/write, and kinesthetic styles being dominant. The lesser role of the visual style may be of limited significance to managers, since most managers' graphic skills are underdeveloped anyway (Knight 1999a, 1999b; Murranka and Lynch, 1999; Wardrope and Bayless, 1999), making it unlikely that this would be a preferred learning style.

The Felder-Silverman Learning/Teaching Style Model (Felder and Silverman, 1988) proposes that individuals have preferences along five bi-polar continua: active-reflective, sensing-intuitive, visual-verbal, sequential-global, and intuitive-deductive. However, metrics are only associated with the first four of these. Hawk and Shah report that this model and associated instruments are still under development and that research on the model's validity and reliability has yet to occur. The Felder-Silverman Model associates particular preferences with each end of the scale: active learners are doers and experimenters, particularly in groups; reflective learners like to work solo, have time to ponder before acting, and take notes in class; sensing learners like facts, data, detail, experimentation, solving problems, practicality, and real-world connections; intuiting learners prefer innovative and abstract ideas and theories, and discovering new possibilities and concepts; visual learners like words, pictures, symbols, flow charts, diagrams, films, demonstrations, and reading; verbal learners like to tape lectures, and discuss and explain things; sequential learners prefer linear, step-by-step information flows, reasoning, and problem-solving procedures; and global learners tend to integrate and synthesize, and intuitively discover connections, patterns, and the 'big picture'. Again, the study tour format provides opportunities for all eight learning preferences. However, study tours appear to be particularly helpful to students weak as global learners (participants appreciate the integrative nature of the visits, integration being an important skill for managers), or weak as active learners (much of the preparatory, briefing, debriefing and on-tour work is done in groups). 
The Dunn and Dunn (1989) Learning Style Model suggests five learning style stimuli, each with subelements: environmental (sound, light, temperature, and room design); emotional (motivation, persistence, responsibility, and structure); sociological (learning alone, in a pair, with peers, with a teacher, and mixed); physiological (perceptual, intake while learning, chronological energy pattern, and mobility needs); and psychological processing (global or analytic, hemisphericity, and impulsive or reflective). Dunn et al. (1995) provide extensive validation of the model (challenged by others, in part) as well as research showing enhanced student performance when teachers take student learning-preferences into account. A survey instrument with 100 items is used to plot student bi-polar preferences on the basis of 20 elements (e.g. prefers quiet or sound, dim or bright light, cool or warm environment, and so on). Again, learning opportunities pre-, on-, and post-tour in the aggregate encompass the full scope of all 20 elements. In other words, whichever learning preferences a student may have, the study tour experience is so varied that all possible preferences will, at some stage, be met.

Finally, the Revised Approaches to Studying Inventory Model (e.g. Duff, 2004) provides scaled measures for three broad study preferences: deep (students look for meaning, enjoy the act of learning, establish links to previous learning, use logic, reasoning, and evidence well, and learn critically); surface (students memorize, have difficulty using logic, reasoning, and evidence, connect less to previous learning, and find studying difficult); and strategic (students self-organize their study routine, manage their time, and learn what is required to excel). Duff has conducted extensive research using confirmatory factor analysis that supports the validity and reliability of the model. Duff's approach only tangentially touches on experiential learning and hence has only limited applicability to study tours, except that they too can offer deep, surface, and strategic learning, discussed later.

Hawk and Shah (2007) point out the lack of comparability across these six models - each approach has its own definition of learning style, and a different theoretical framework: being variously experiential (Kolb), phenomenological (Gregorc), sensory/perception (VARK), outcome-focused (Duff), or a combination of two or more of these (Felder-Silverman, and Dunn and Dunn). Hawk and Shah conclude from this and their own research in teaching MBA students that: (a) no one model captures the richness of the learning styles phenomenon; (b) a demonstrated awareness of people's learning style preferences, including minority groups', helps connect with people; and (c) best results in terms of more effective and deeper learning are likely to be obtained when a rich mixture of teaching approaches is used. For example, global learners like to see the whole picture first in order to better understand how the parts fit together. Running study tours involves a wide range of learning activities: lectures, readings, handouts, maps, diagrams, simulations, role playing, observations, documenting, field trips, taking photos, discussions, conversations, group assignments, logs, personal journals, note taking, homework, checklists, worksheets, written and verbal feedback, doing research, humor, interviewing, hands-on-experience, translating, physical activities, and hence involves the visual, aural, kinesthetic, read/write, and even olfactory senses. It is hard to conceive of a teaching/learning activity that could be richer than this.

The above analysis could be interpreted as implying that all study tour formats produce comparable learning outcomes. In the next sections we describe the pressures for and popularity of study tours, describe two quite different approaches to study tours, and explain how they produce different learning outcomes using the above analysis as a framework.

\section{LEVELS OF LEARNING}

The primary purpose of study tours is to promote participant learning, but clearly the quality of that learning can vary. Student learning is said to range from 'surface' levels to 'deep' levels, with combinations of surface and deep learning in between (Aram and Noble, 2000). This notion of surface and deep-level learning is somewhat different from Duff's (2004) conception. Surface learning here does not refer to students memorizing material; struggling with logic, reasoning, and evidence; and having difficulty connecting to previous learning; but sees the learner in the role of a passive 'consumer' of facts, and involving procedures and techniques typically employed by an 'expert'. In relation to study tours, this kind of learning is often referred to, somewhat unflatteringly perhaps, as industrial tourism (Bergstrom, 1994). Intensive study tours on the other hand are more akin to Duff's notion of deep-level learning since students look for meaning, enjoy the act of learning, establish links to previous 
learning, use logic, reasoning, and evidence well, and learn critically. At this level of learning, students abstract meanings and come to understand 'reality' for themselves.

Touring manufacturing plants was particularly popular during the 1990s, perceived as a means of benchmarking and improving an organization's manufacturing capabilities (e.g. Grayson, 1994; Upton and Macadam, 1997). Here, visits involve guided inspection of a production facility, usually with commentary, but with limited opportunity for questions and answers or for developing much understanding of the host organization's processes and strategies. For those interested in operations in a manufacturing context, industrial tourism offers much to see that is stimulating and hence can offer valuable insights - being able to observe kanban, just-in-time, automated processes and other operational systems is often enlightening and instructive. Schools running tours with a focus on operations, like Seattle University, report that "student response...has been phenomenal" (Brown and Leong, 1996: 9-10). However, for those who are interested in less visible topics such as organizational behavior, global leadership, marketing, or corporate strategy, whether in manufacturing, service, or research sectors, industrial tourism is likely to offer limited benefits. In addition to a focus on the operational side of manufacturing, two other factors limit the benefits of industrial tourism: communication in manufacturing settings can be difficult and shallow - difficult due to noisy environments and shallow because guides, though knowledgeable about the processes being shown, generally are not qualified to comment on high-level corporate issues. This can restrict the learning to direct observations made in the plant at the expense of understanding broader policies and processes in the organization's overall strategy.

Nonetheless, at a surface level, 'industrial tourism' tours can provide benefits by showing students, particularly those without work experience, how operational processes work; illustrating theoretical concepts, showing how theory is put into practice (or not); generally making abstract concepts more concrete; and providing an alternative teaching method to classroom activities.

Given the limits of industrial tourism, the authors became involved in developing a study tour program at a leading Australian business school that provides a more intense, deeper level learning experience than industrial tourism, and includes different kinds of organizations. Eight intensive learning study tours have been conducted since 1999. Visits typically include discussions with a range of senior executives covering leadership behaviors, policies and systems, sustainability, organizational culture, innovation, and knowledge management. However, when companies had other key competencies critical to their performance in the marketplace (e.g. marketing for Swatch), students were able to broaden their area of concern. A plant tour, where applicable, normally follows, often finishing with another interactive session to explore further questions. Participants debrief each visit within a few hours of its completion, and are encouraged to use a diary for private reflection.

At a deeper level of learning, students can obtain greater appreciation of managers operating under real conditions of incomplete and ambiguous information, often with unpredictable outcomes. By directly interacting with senior managers of organizations first-hand, students are enabled to see the limitations of the traditional 'Newtonian' approaches that characterize many business school curricula. Through their observations and questioning, students see that the old assumptions of closely linked cause-and-effect relationships; linear predictability; single 'correct' outcomes; and relying on rational, objective processes are very limiting in complex, dynamic organizations (Bennis, 1985; Mintzberg, 1979; Wheatley, 1999). Under this study tour format, students become active agents in interpreting and abstracting meaning from experience, rather than having the experience interpreted through teachers and other outside agents (Aram and Noble, 2000). Learners need to make an active effort to relate what they experience on the tour to other parts of their lives. This approach assumes that there is no one right answer, that students reach their own answers, and most importantly, that this is appropriate in a university environment. The approach reflects Schon's (1987) 'reflection-in-action' concept, and Argyris and Schon's (1978) 'double-loop' learning. In double-loop learning, people examine their own behavior, take responsibility for their own action (or inaction), and examine the reasons and motives behind what they are shown (Argyris, 1994). On intensive learning study tours, students experience organizations as complex adaptive systems struggling to manage knowledge or as entities on the 'edge of chaos' struggling to adapt and survive (Merry, 1995). Global managers need to deal with such uncertainty and cope well with changing conditions, balancing the tensions between global and local conditions (Bingham, Felin, and Black, 2000; Gregersen et al., 1998). 
Through an intensive learning tour, students can also gain insight into the 'shadow' side, as opposed to the legitimate part of the organization that is explicit, subject to rules, policies, and other organizational mechanisms. In the shadow organization, people form their own networks, communication channels, play their political games, and avoid the bureaucracy to get their work done (Mintzberg, 1979). Industrial tourists can easily miss the shadow side, whereas intensively prepared participants are well-versed about each host organization, and therefore in a better position to probe beneath the surface, even in the short time available.

Given that discussions usually take place in settings that allow intensive, and yet relaxed, communication to occur, even quite delicate issues can be raised. Thus, in the case of a car manufacturer, representatives of the organization discussed the reasons for the failure of a takeover of another car manufacturer quite openly. To some extent the willingness to discuss problem areas of the organization openly is an intercultural issue. We find the German and Swiss organizations that we visit extraordinarily open. Brown and Leong (1996: 12) report a similar experience for the Ohio State tours to Mexico and Brazil. Such frankness once again supports deep-level learning.

Our students report intense learning experiences, which continue to grow after the tour and bring benefits to them at work. A typical comment expressed by one participant on our 2000 tour: "We are all quite fascinated by how much we view activities in our own organizations through very different eyes as a result of the experiences we gained through our visits to the companies and the discussions we had through the course and especially on tour with you and the members of the Group ... One of the things that I'm finding though is that my appreciation of what I've absorbed deepens the further away it gets."

\section{CONSIDERATIONS IN DESIGNING STUDY TOURS}

Many options are available in designing a study tour, including where to go, what kind of organizations to visit, and how many visits to schedule each day. Brown and Leong (1996: 11) concluded that after taking travel time into account, visiting only one company per day was optimal. We came to a similar conclusion for a variety of reasons, but particularly because we wanted to enable deep levels of learning to occur. A less crowded schedule allows participants more reflection and discussion time between visits, as well as providing more exposure to each host organization. All types of organizations can be usefully visited. We have taken students into organizations representing a wide range of industry sectors, including manufacturing (e.g. cars, automotive suppliers, mixing machines, white goods, watches, beer, soft toys, optical goods, computers, pharmaceuticals), services (e.g. insurance, IT solution providers, trade fairs, museum), and research.

As to where to go, there is no assumption implicit in our tours that best practice is exclusive to Europeanbased organizations. However, in the English-speaking world, most management cases and information tend to come from the US, in other words, students tend to receive a very one-dimensional view of management. For budding or already practicing global managers we believe it is essential to be exposed to quite different cultural, social, and business perspectives. To maximize the learning experience during the corporate visits still further we prefer locations such as Germany and Switzerland where local managers have an excellent command of English thereby obviating the need for translators. (Obviously, where translating services are required the amount of material that can be covered is reduced, and the quality of communication suffers).

Regarding the length of tours, to be able to have a reasonable number of visits, and make the long trip from Australia and Asia to Europe worthwhile, means that two weeks and visiting eight organizations seems optimal. More than two weeks would be difficult for many students. This may be because our school's students tend to be older than many MBA students (average age around 35), most are in management roles, are studying part-time, and have family commitments. Furthermore, we have found that it takes about one week for students to cease analyzing, interpreting, and criticizing their hosts from their narrow Anglo/US perspective and to become more accepting of, if not to say enthused with, alternative approaches to running businesses. However, at this stage we have no hard empirical data to substantiate this perception.

We also opted for a self-directed group learning approach on our study tours, based on the idea that adults are capable and motivated to learn from their own activity, and that group learning facilitates such learning (Drafke, 
Schoenbachler and Gordon, 1996; James, 1997). We aim at creating a learning environment in which participants can relate to one another, share their ideas and insights, discuss the meanings and interpretations of company experiences, and work in groups to achieve intense self-learning outcomes. Students take control of their learning environment within the framework of the assessment requirements for the unit. The teacher's role becomes that of facilitator and guide, but not interpreter. This can frustrate some students, who constantly want to 'hear what you think', and have the teacher tell them what is 'right', or if their interpretation is 'correct'. It is important therefore to emphasize pre-tour that the tour involves a self-directed learning process.

Another decision relates to whether to integrate academic credit into a study tour or not. In our experience, doing so encourages deep-level learning and is appropriate for an intensive study tour. By engaging in extensive pretour preparation, informed participants are able to bring higher-level strategic thinking to meetings with the hosts. This intensive preparation culminates in insightful questions, which raises the learning potential from each visit for both hosts and visitors. Our study tour hosts often tell us that "we gained so much from the discussions last year...".

Various forms of assessment can be used during the tour to aid learning, including having students complete a checklist after every visit as the University of South Dakota does (Wymar, 1996). This promotes individual learning, and is particularly valuable because even one visit per day is intensive, providing little time for students to reflect, deepen their thinking, and link the learning to practice. Gordon and Smith (1992) found that lectures combined with company visits and guest speakers enhanced the active learning. On our tours, groups are expected to manage the visit to their assigned companies, which includes providing a pre-visit briefing en route to the company. In addition, following each visit, a formal debriefing session is facilitated by the student group assigned to that day's host organization. Students are also expected to provide culturally-appropriate welcome and thank-you speeches to the hosts, to ensure active participation during plant tours, and to facilitate lunch discussions with the host representatives. Further, we set a major integrative group assignment to be completed over the six weeks following the tour. This allows group members to assimilate and refine their learnings over time. Participants are also assessed on general tour participation and support for others.

In this globalizing world, people need to understand business etiquette in different cultures (Cales, 2000) and appreciate cultural diversity (Goldsmith et al., 1999/2000). Some tours therefore include intercultural issues as part of the course (Schuster et al., 1998), whereas others allow students to absorb the cultural side through sightseeing and simply being abroad (e.g. Gordon and Smith, 1992). In our tours, we do not formally assess the intercultural side, but provide instruction, role playing, and reading in German and Swiss cultural ways, and coach students during the tour by pointing out intercultural differences. Hotels with local character are chosen in preference to international chains, and students are coached in local customs during the tour. To further enrich the intercultural learnings, students from the school's campuses in Singapore and Hong Kong participate in all phases of the tour.

The intense preparation culminates in detailed reports and sets of questions that are sent to the respective host company before the visit. This, coupled with a pre-visit meeting about four weeks before the group visit, typically results in meetings with many more senior executives than the organization had originally planned. Since the organizations are aware that issues will be raised that are way beyond the competency of most industrial tourism guides, organizations make representatives of the appropriate caliber available. This is important to an intensive learning experience because interaction with senior executives at the host enterprise greatly enhances the learning. On our tours, the organizations' representatives typically range from CEO to VP or departmental head level. Given that the discussions always take place in accordance with a previously agreed upon agenda, some representatives of the organization only need be present for one or two hours, whereas others were present for the whole day. This usually includes the person who organizes the event on the organization's side. In the course of a day's visit, we have had as many as 11 senior managers of an organization joining the discussion.

Finally, we endeavor to ensure high quality across all aspects of our tours - quality of hosts and participants, academic, cultural, intercultural, organizational, and logistics. This has meant a number of things. Host organizations are chosen on the basis of their longevity (sustainability), industry standing (e.g. peer rankings), reputation (e.g. rankings on best-employer lists), rankings on sustainability indices (e.g. Dow Jones Index), and 
other indices that suggest quality, profitability, and sustainability. Participants are already highly selected in so far as our school selects students on the basis of their academic qualifications and work experience. In addition, they are required to have taken certain subjects as a prerequisite to being able to participate in the tour, and achieved a criterion grade point average. The European tours are accompanied by two bilingual professors who are thoroughly familiar with Europe. One academic functions as liaison person between the host organizations and the school, as well as tour manager. The other professor is responsible for the production of the course outline, facilitates student meetings, and sets and evaluates assignments. Both facilitate meetings with the hosts and participates in debriefing the visits. At the organizational and logistical level, ensuring the success and smooth running of a tour requires highly detailed planning, considerable effort, diplomatic skill, and enormous good will as others have reported (e.g. Birkner and Birkner, 1997; Darnow, 1988). In line with the objective of offering students a best practice tour, every attempt is made to ensure that all arrangements before, during, and after the tour are handled efficiently and in a customer-friendly manner. This has required the generation of extensive promotional and academic material, organizational schedules and tools, and feedback instruments. To ensure that the tour itself 'runs like a Swiss watch', the tour manager undertakes a trial run, during which he visits all the hotels, companies, and major tourist sites to ensure quality control, finalize details, and ascertain travel times and optimal travel routes. The school has found that some of the host companies 'upgrade' the visit as a result of the trial run. This could mean having additional or more senior staff made available for the visit, spending more time with the companies, or the groups being invited to lunch in the VIP dining room instead of in the canteen.

In summary, the format of our study tours in terms of country destination (social, cultural, and businessapproach divergence, but English language competency), range of organizations (manufacturing, service, government, research), length of tour (two weeks), length of individual visits (1 visit per day), range of pedagogic techniques (self-learning, assessed, accredited, etc. - for full list, see above), intensity of preparation (in-depth briefing report and 15 searching questions), quality management at all stages (selection of students, selection of hosts, thorough editing of briefing reports, qualification of academics, conducting trial-run), and (de)briefings (pretour, on-tour, and post-tour), provides for an extraordinarily rich and deep-level learning experience as attested to formally and informally by participants.

\section{CONCLUSION}

In the process of proposing and examining various learning styles and preferences, authors such as Kolb (1984), Gregorc (1997), Fleming (2001), Felder and Silverman (1988), and Dunn and Dunn (1989) have identified and categorized a plethora of learning activities and modes that can occur singly or in combination. This can include (in alphabetical order): arguments, audio tapes, bibliographies, books, brainstorming, cartoons, case studies, charts, checklists, color, constructing, conversations, creating possibilities, debates, demonstrations, designs, diagrams, discussion, documenting, doing research, drama, essays, examples, field trips, flowcharts, fonts, graphs, group work, hands-on experience, hand-outs, humor, instructional media, interviewing, investigations, keeping journals, lectures, light, mapping, maps, mobility, motivation, multiple-choice, music, note-taking, outlines, persistence, physical activity, presence of authority figure, problem solving, reading, real-life examples, reports, responsibility, role play, seminars, simulations, sound, spatial arrangements, structure, temperature, term papers, time, verbal feedback, video, writing, written feedback, working models, and worksheets. International study tours conducted by the authors have involved all of the activities and modes of learning shown in italics on the above list. According to participants this rich learning format has produced deep-level and long-lasting learning. Much of this richness is not available on 'industrial-tourism' visits, particularly on the preparatory, self-centered, and interactive side, and hence learning occurs more at a surface level. Other factors influencing the quality and depth of learning are whether student work is assessed, the visits are part of accredited courses, and the overall quality of the tour. However, notwithstanding the limitations of 'industrial tourism', both surface-level and deep-level learning tours enjoy great popularity. 


\section{REFERENCES}

1. Aram, E., and Noble, D. (2000). Educating prospective managers in the complexity of organizational life. Centre for Complexity \& Management Working Paper.URL http://www.herts.ac.uk/business/centres/cmc/pub12.htm.

2. Argyris, C. (1994). Good communication that blocks learning. Harvard Business Review, 72, 77-85.

3. Argyris, C., and Schon, D. (1978). Organizational Learning: A Theory of Action Perspective. AddisonWesley: Reading, MA.

4. $\quad$ Bennis, W. (1985). Leaders: The Strategies for Taking Charge. Harper and Row: New York.

5. Bergstrom, R. Y. (1994). Industrial tourism may make you happy. Production, 106, 60.

6. Bingham, C. B., Felin, T., and Black, J. S. (2000). An interview with John Pepper: What it takes to be a global leader. Human Resource Management, 39, 287-292.

7. Birkner, L. R., and Birkner, R. K. (1997). The plant tour: A tool for improving performance. Occupational Hazards, 59, 55-56.

8. Brown K. A., and Leong K. (1996). International study tours: Options and approaches. Decision Line, May, 9-12.

9. $\quad$ Butler, K. A. (1986). Learning and Teaching Style in Theory and Practice. Learner's Dimension: Columbia, CT,

10. Cales, M. (2000). Etiquette for the global market. Management Review, 89, 7.

11. Cornuel, E. (2007). Challenges facing business schools in the future. Journal of Management Development, 26(1), 87-92.

12. Darnow, B. (1988). Conducting a workplace tour. Management Solutions, 33, $32 \mathrm{ff}$.

13. Drafke, M. W., Schoenbachler, D. D., and Gordon, G. L. (1996). Alive and passive teaching methodologies: Student outcomes over a semester course. Marketing Education Review, 6(1), 9-18.

14. Duff, A. (2004). Approaches to learning: The revised approaches to studying inventory. Active Learning in Higher Education, 5(1), 56-72.

15. Duke, C. R. (2000). Study abroad learning activities: A synthesis and comparison. Journal of Marketing Education, 22, 155-165.

16. Dunn, R., and Dunn, K. (1989). Learning Style Inventory. Price Systems: Lawrence, KS.

17. Dunn, R., Griggs, S. A., Olson, J., Beasley, M., and Gorman, B. S. (1995) A meta-analytic validation of the Dunn and Dunn model of learning-style preferences. Journal of Educational Research, 88(6), 353-362.

18. Felder, R. M., and Silverman, L. K. (1988). Learning styles and teaching styles in engineering education. Engineering Education, 78(7), 674-681.

19. Fleming, N. D. (2001). Teaching and Learning Styles: VARK Strategies. N.D. Fleming: Christchurch, NZ.

20. Goldsmith, M., Walt, C., and Doucet, K. (1999/2000). New competencies for tomorrow's global leader. CMA Management, 73, 20-24.

21. Gordon, P., and Smith, D. K. (1992). Planning, organizing, and executing short term international exposure for U.S. students of marketing and business. Marketing Education Review, 2(1), 47-54.

22. Grayson, C. J. Jr. (1994). Back to the basics of benchmarking. Quality, 33, $20 \mathrm{ff}$.

23. Gregersen, H. B., Morrison, A. J., and Black, J. S. (1998). Developing leaders for the global frontier. Sloan Management Review, 40, 21-32.

24. Gregorc, A. F. (1997). Inside Styles: Beyond the Basics. Gabriel Systems: Maynard, MA.

25. Hawk, T. F., and Shah, A. J. (2007). Using learning style instruments to enhance student learning. Decision Sciences Journal of Innovative Education, 5(1), 1-19.

26. James, K. (1997). The complexity of power relations: An interdisciplinary approach to complex systems thinking. The Strategy \& Complexity Seminar. Warwick Business School Business Processes Resource Centre. URL http://bprc.warwick.ac.uk/kim-sem.htm. 17 December.

27. Kayes, A. B., Kayes, D. C., and Kolb, D. A. (2005). Developing teams using the Kolb Team Learning Experience. Simulation and Gaming, 36(3), 355-363.

28. Knight, M. (1999a). Management communication US MBA programs: The state of the art. Business Communication Quarterly, 62(4), 9-32. 
29. Knight, M. (1999b). Writing and other communication standards in undergraduate business education: A study of current program requirements, practices, and trends. Business Communication Quarterly, 62(1), 10-28.

30. Kolb, D. (1984). Experiential Learning: Experience as the Source of Learning and Development. PrenticeHall: Englewood Cliffs, NJ.

31. Merry, U. (1995). Coping with Uncertainty: Insights from the New Sciences of Chaos, Self-Organization, and Complexity. Praeger: Westport.

32. Mintzberg, H. (1979). The Structuring of Organizations: A Synthesis of Research. Prentice-Hall: Englewood Cliffs, NJ.

33. Murranka, P. A., and Lynch, D. (1999). Developing a competency-based fundamentals of management communication course. Business Communication Quarterly, 62(3), 9-23.

34. Oddou, G., Mendenhall, M. E., and Ritchie, J. B. (2000). Leveraging travel as a tool for global leadership development. Human Resource Management, 39, 159-172.

35. Schon, D. A. (1987). Educating the Reflective Practitioner. Jossey Bass: San Francisco.

36. Schuster, C. P., Zimmerman, R. O., Schertzer, C. B., and Beamish, P. W. (1998). Assessing the impact of executive MBA international travel courses. Journal of Marketing Education, 20(2), 121-132.

37. Thomas, H. (2007). An analysis of the environment and competitive dynamics of management education. Journal of Management Development, 26(1), 9-21.

38. Upton, D. M., and Macadam, S. E. (1997). Why and how to take a plant tour. Harvard Business Review, 75, 97-106.

39. Wardrope, W. J., and Bayless, M. L. (1999). Content of the business communication course: An analysis of coverage. Business Communication Quarterly, 62(4), 33-40.

40. Wheatley, M. J. (1999). Leadership and the New Science: Discovering Order in a Chaotic World. $2^{\text {nd }}$ edition. Berrett-Koehler: San Francisco.

41. Wymar, B. (1996). Twenty five years European business and economic studies tour. South Dakota Business Review, 54(3), 1-2. 
NOTES 